\title{
PSYCHE
}

VOL. XXI.

JUNE, 1914.

No. 3

\section{A NEW DIPLOPOD FROM THE GALAPAGOS ISLANDS WITH NOTES ON THE CHILOPODS.}

\section{By Ralph V. Chamberlin.}

The type specimens of the interesting new diplopod here described were collected on Chatham Island in the Galapagos Archipelago in 1898 and 1899 , presumably by R. E. Snodgrass as a member of the Stanford Expedition of 1898-1899.

Of the five species of chilopods known from the Galapagos Islands, specimens of all of which were secured by the expedition mentioned, four appear to be indigenous. The five species are as follows.

\section{Orphnaeus brevilabiatus (Newport).}

One female from Hood's Island (May 18, 1899), between which and specimens from Central America, the West Indies and elsewhere I fail to detect any essential differences. A very common geophiloid throughout the warmer parts of both hemispheres.

\section{Mecistocephalus parvus Chamberlin.}

I at first regarded the specimen of this species, which were from Clipperton Island (November 23, 1898), as belonging to $M$. punctifrons Newport; but a more critical study of material from India, the East Indies and different parts of warmer America has convinced me that Newport's species has been too broadly conceived by Haase and others and that several clearly distinct species have been confused under the name. The confusion has resulted largely because the species agree in having the number of pairs of legs constantly 49 , and do not differ in various other characters that ordinarily serve for the discrimination of species in related families. The species dominant in Java and the Malay Peninsula is a different one from the typical punctifrons of India; and the species occurring in the Bermudas, West Indies and South and Central America is also different and must bear the name guildingi applied 
by Newport to specimens from St. Vincent. The types of $M$. parvus are small slender specimens, near $20 \mathrm{~mm}$. in length. The cephalic plate is proportionately broader than in the other species mentioned, being from 1.61 to 1.63 times longer than wide; whereas in guildingi it is from 1.98 to 2.1 times longer than wide, and in the Javan species (for which Meinert's name cephalotes must probably be resurrected) from 1.68 to 1.71 times longer, while careful micrometer measurements of numerous specimens of punctifrons from India showed the cephalic plate in adults to vary from 1.88 to 1.91 times longer than wide, the plate in partly grown specimens being near 1.85 and in the youngest ones 1.8 times longer than wide.

3. Pectiniunguis albemarlensis Chamberlin.

This species is very close to $P$. americanus which is apparently common on both the Pacific and eastern coasts of Mexico and has been taken on the Florida Keys. The Galapagos species has near the same number of legs (61 pairs) as americanus and is also marked with a similar geminate dark stripe along the dorsum. The head is distinctly broader, the ratio of length to breadth in the type being 57: 52, while the basal plate is longer, being but 2.5 times wider than long as against 3 times in americanus. The ventral pores are more numerous and the area occupied on each sternite materially greater. Of the two other known species of Pectiniunguis as now restricted, one is from Cuba and the other from Colombia. In California occur several species of a related genus which I have recently named Nyctunguis. One female of $P$. albemarlensis was secured on Albemarle Island at Iguana Cove (December, 1898).

4. Cryptops navigans Chamberlin.

Two specimens taken on Clipperton Island November 23, 1898.

5. Scolopendra galapagoensis Bollman.

Specimens of this species were taken on Hood, Chatham, Bindloe, Narborough and Albemarle Islands. It seems to be much the commonest chilopod of the Archipelago, being the only one in fact that was taken on more than one island. Its affinities seem to be closest to the group of the division Collares occurring in the warmer parts of America.

The new diplopod Nesodesmus is a member of the Pyrgodesmidæ. 
Nesodesmus gen. nov.

Head strongly granulo-tuberculate. Antennæ short, clavate, with the fifth article thickest and much the longest.

Dorsum strongly elevated and convex; strongly sculptured, being densely granular and tuberculate over the entire surface of keels as well as remaining portion of metazonites; a longitudinal row of larger tubercles each side of the median line, the tubercles increasing in size caudad with a tendency to be confluent. Spiracles on segments $5,7,9,10,12,13,15$ and 16 , each opening through a thick, subcylindrical papilla borne on the marginal lobe second from the caudal corner. Keels large, depressed, covering the legs from above, almost contiguous, laterally mostly deeply lobate, the lobes either 3 , or by subdivision of the anterior one, 4 in number, the caudal border of keel also deeply lobate and the anterior one of most less strongly lobed.

First dorsal plate broadly extended and covering the head as in Lophodesmus. Typically showing 12 rounded teeth or crenations along the anterior margin corresponding to the twelve lobules marked off on the border by 11 radial sulci.

Anal tergite short and broad, its caudal margin convex in general outline; a broader median portion notched at the middle on each side of which are two sharply separated narrow lobes or teeth. In the type species the keels of the nineteenth tergite are produced caudad a little beyond the caudal margin of the anal plate.

Genotype: $N$. insulanus sp. nov.

This genus is apparently most closely allied with Lophodesmus as represented in Central America and Mexico. It is separated chiefly because of the difference in the position of the spiracle and the form of its papilla on the carinal margin, this occurring near the middle of the side instead of at the caudolateral corner; in the deeper lobation of the lateral border and the larger number of its divisions and in the lobation of the anterior as well as of the caudal border; and in having the entire dorsal surface of the keels as well as of the median portion of the metazonite strongly tuberculate. The first tergite has its anterior border divided into 12 lobules instead of the $\mathbf{1 0}$ characteristic of species of Lophodesmus thus far known. 
Nesodermus insulanus sp. nov.

Dark brown, irregularly dusky. Vertex of the head like the dorsum, but the remaining portions together with the antennæ and legs a paler brown or brownish yellow. Prozonites ventrally yellow.

Vertex and upper frontal region of head tuberculate with corresponding dusky or black areolation. Other parts with corresponding areolæ limited by a network of impressed lines.

Antennæ short, strongly clavately thickened distad, the fifth article being much the longest and thickest; sixth article next in thickness and length, with the seventh more slender and much shorter. Hairs on distal articles subdense, all very short.

First dorsal plate with its border projecting horizontally anteriorly and laterally widely beyond the head. Much longer than the other tergites. Caudal margin mesally straight. Border divided by radial sulci into 12 lobules each of which projects as a wide, low, rounded tooth or crenulation at the margin. Lobules finely granular, the convex median portion of the plate appearing more coarsely and densely tuberculate.

Sides of body parallel or nearly so excepting towards ends. Keels of dorsal plates large, extending laterally over the feet. Keels of the second tergite bent conspicuously cephalad, those of the next three less and less so and the remaining ones back to the eighteenth with anterior and caudal margins nearly straight and parallel and at right angles to the long axis of the body. Keels of the eighteenth segment bent caudad. Keels increasing in length (i. e., in longitudinal diameter) from the third caudad, those of the second being longer than those of the third. Each keel of the second plate with lateral margin showing 3 rounded teeth with corresponding divisions of border separated by sulci; the third and fourth plates with borders of keels similar but teeth better separated. On keels of the fifth tergite the lateral incisions of keels extend mesad along sulci much farther, dividing the border into 3 narrow, distally rounded lobes from the median of which projects the pale subcylindrical spiraculiferous papilla; in all succeeding plates the anterior lobe is subdivided thus giving 4 distinct lobes separated by deep narrow incisions replacing the sulci of the most anterior plates; the most anterior lobe extending farthest ectad, the posterior one least. Caudal edge of keel of all plates 
showing 2 (or 3) smaller lobes and the anterior margin presenting a corresponding number of still smaller lobes or teeth excepting on the second and third plates, the lobes or teeth becoming larger caudad. Spiraculiferous papillæ smooth, the dorsal surface of the rest of the keels and of the remaining portion of metazonites densely and strongly coarsely granular and tuberculate. Caudal margin of metazonites between keels presenting 9 or 10 distinct rounded teeth or crenulations which are weak or in part obliterated on the plates cephalad of the sixth. Two longitudinal rows of large tubercles, there being in each row 3 tubercles on each metazonite, the mostcaudal of these being on a lobe or tooth of the caudal margin; tubercles increasing in size from segment to segment in in going caudad, the caudal ones of the eighteenth and nineteenth segments in particular being large and conical. Keels of the nineteenth segment produced caudad so that the posterior edge is parallel with long axis of body or nearly so; between these keels 4 stout conical teeth project caudad and nearly attain level of caudal margin of the anal tergite when viewed from above.

Anal tergite short, nearly concealed from above by the nineteenth plate. Presenting a broad, mesally notched, median lobe and on each side of this and farther proximad 2 conical teeth separated by deep incisions.

Anal scale small; on its caudal margin presenting 2 conspicuous tubercles, each of which bears a long bristle.

Sternites very narrow; longitudinally sulcate.

Trochanters of the legs relatively very long.

Ducts of testes opening through simple perforations on the ventral surface of swellings on the coxæ of the second legs, these swellings commonly contiguous at the median line.

Gonopods of male each presenting a mesally hollow subhemispherical basal division apparently capable of being closed against the corresponding lobe of the opposite gonopod. Distal division short and proportionately broad; distally presenting a short process projecting caudad and a larger subfalciform anterior process from the caudal concave surface of which bends caudad the conically pointed tip of a third process which seems to be the stylus.

Length: 9.5 to $11.5 \mathrm{~mm}$; width 2 to $2.25 \mathrm{~mm}$. Locality: Galapagos Archipelago; Chatham Island (May 21, 1899). Probably collected by Snodgrass.) Thirteen specimens were secured. 

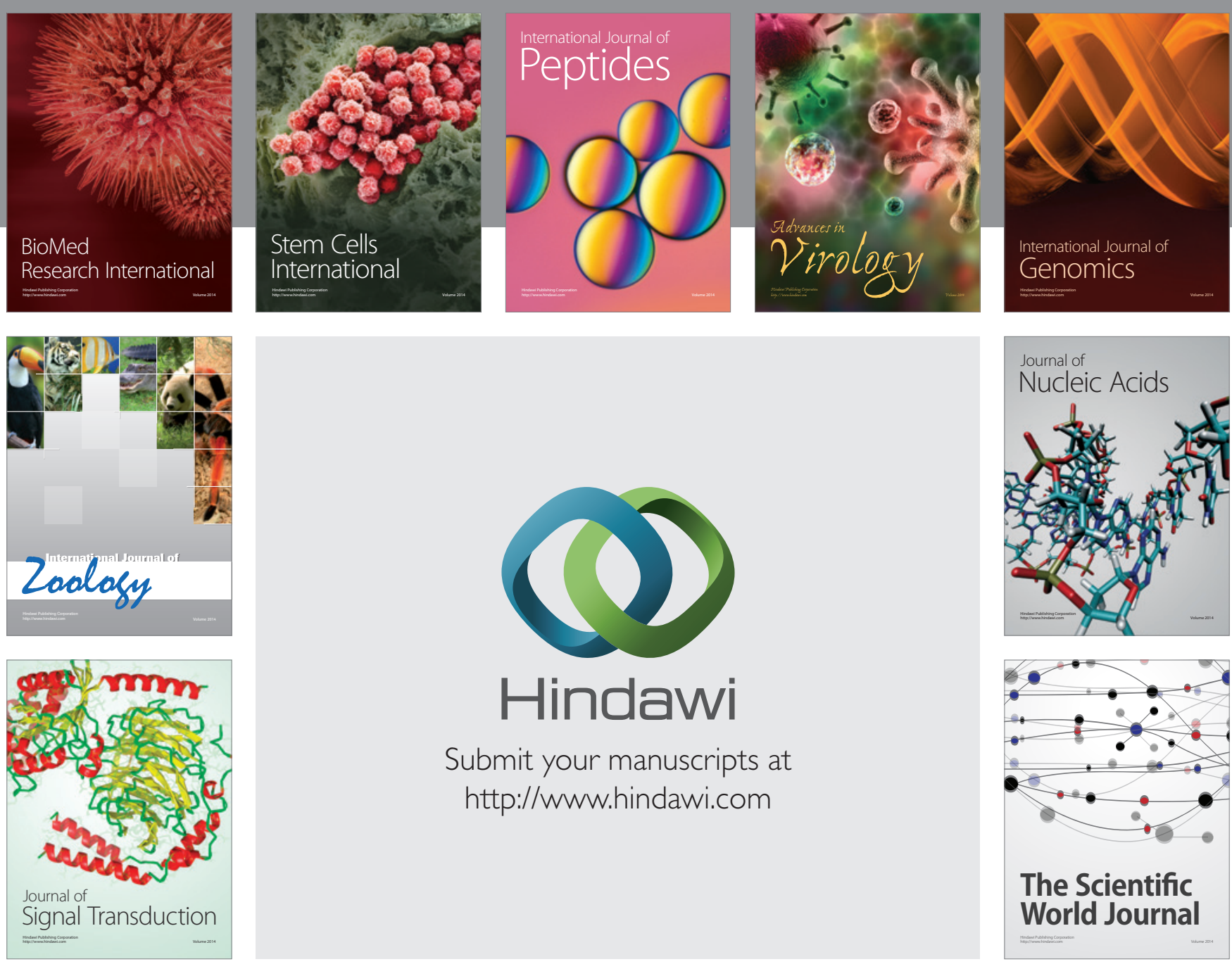

Submit your manuscripts at

http://www.hindawi.com
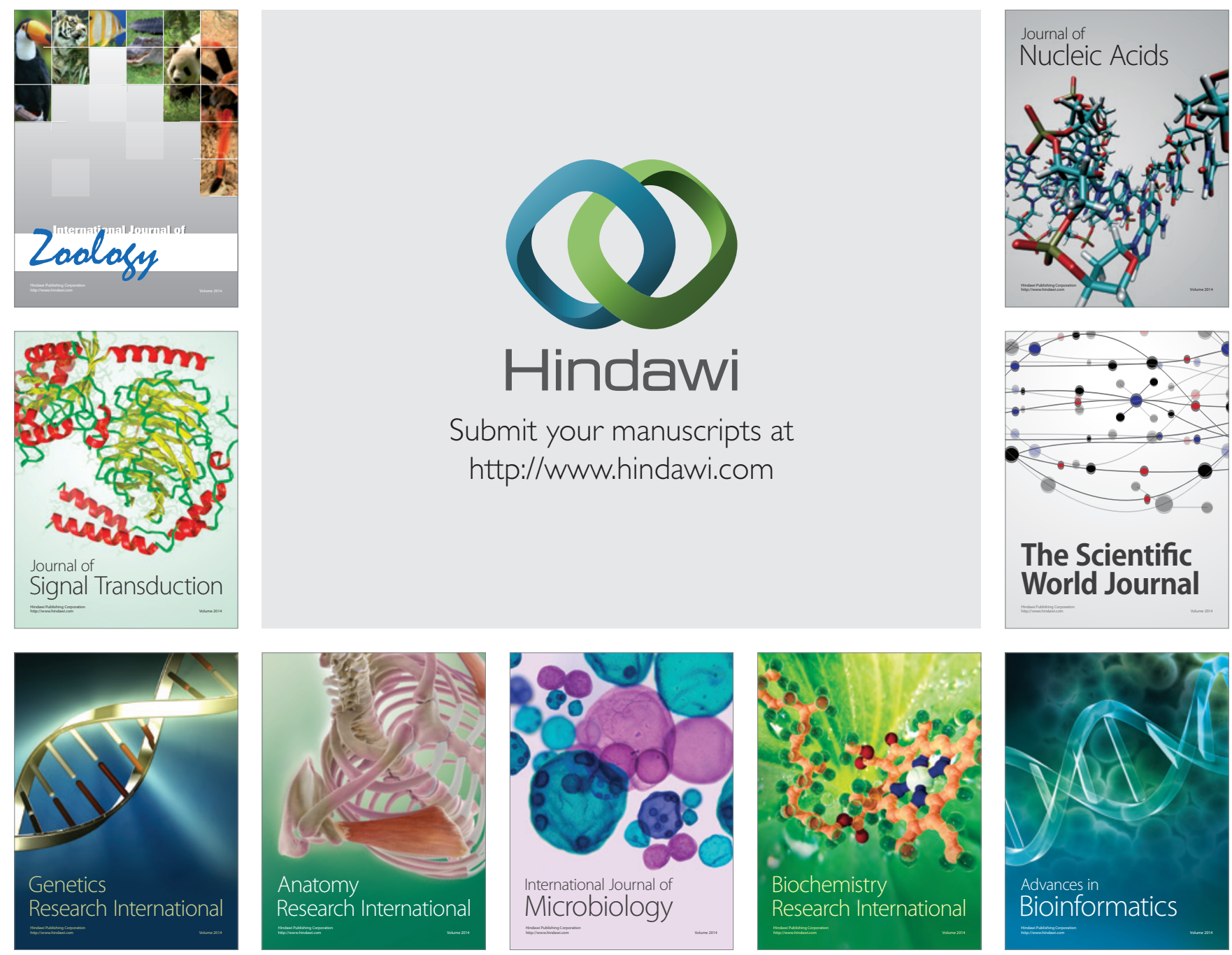

The Scientific World Journal
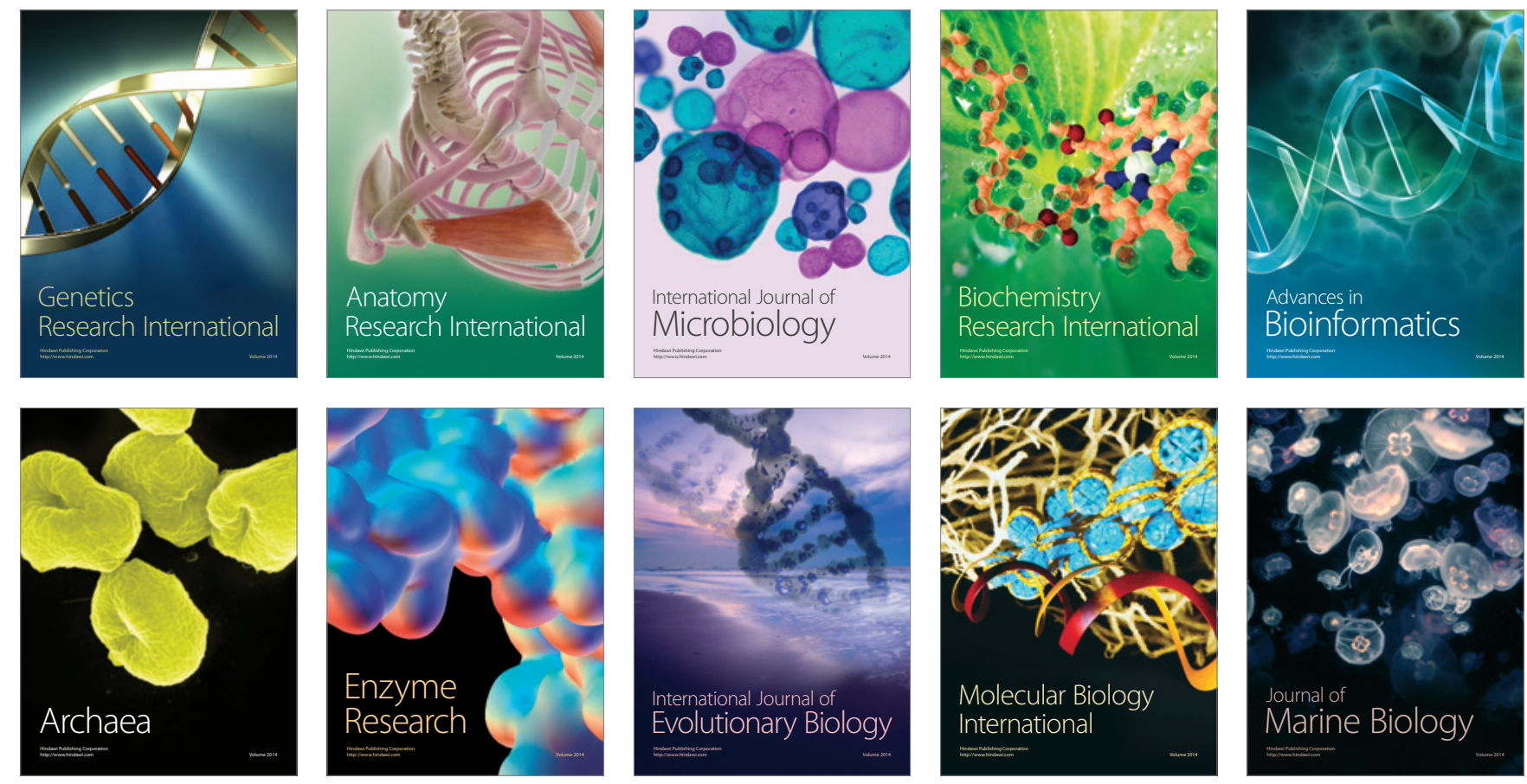